\title{
Carpal tunnel surgery: predictors of clinical outcomes and patients' satisfaction
}

\author{
Ehsan Alimohammadi ${ }^{*}$ (D), Seyed Reza Bagheri ${ }^{2}$, Homa Hadidi ${ }^{3}$, Parisa Rizevandi ${ }^{4}$ and Alireza Abdi ${ }^{5}$
}

\begin{abstract}
Background: Carpal tunnel syndrome (CTS) is the most common peripheral neuropathy. Moreover, carpal tunnel release (CTR) surgery generally has excellent results. The present study aimed to investigate the predictors of clinical outcomes and satisfaction in patients with CTR.

Methods: In this observational prospective cohort study, 152 patients with open carpal tunnel release surgery were investigated. Complete clinical examinations were performed and recorded before the surgery, two weeks after the surgery and 6 months after the surgery. The Boston Carpal Tunnel Questionnaire (BCTQ) were assessed on admission and at last follow-up visits to evaluate clinical outcomes. Patients' satisfaction was determined by a 10-point verbal descriptor nominal scale ( $1=$ very poor, $5=$ fair and $10=$ excellent) and recorded during the last follow -up visits.
\end{abstract}

Results: Among 152 patients who were investigated, there were 118 (77.6\%) females and 34 (22.36\%) males. Overall, surgery improved the outcomes based on Symptom Severity Scale (SSS) and Functional Status Scale (FSS) $(P<0.05)$. Most of the considered variables did not show significant effects on clinical outcomes and patients' satisfaction. However, duration of symptoms and electrophysiological severity were the predictors of the change score in $\operatorname{SSS}(P<0.05)$. As well as, age was the only predictor of the change score in FSS $(P<0.05)$. Finally, according to the linear regression model, the pre-operative grip strength and age were the independent predictors of post-operative satisfaction $(P<0.05)$.

Conclusions: Results of the present study revealed that there was a significant improvement in clinical outcomes after CTS surgery. Stronger pre-operative grip strength and younger age were independent predictors of higher post-operative satisfaction. These results can be used in pre-operative counseling and management of post-operative expectations.

Keywords: Carpal tunnel syndrome, Clinical outcomes, Patients' satisfaction, Boston carpal tunnel questionnaire, Symptom severity scale, Functional status scale

\section{Background}

Carpal tunnel syndrome (CTS) is the most common peripheral neuropathy[ [1]. Its prevalence reported between 1 to $16 \%$ in the general adult population $[2,3]$.

CTS is characterized by numbness or tingling in the sensory distribution of the median nerve. In some cases, CTS can be accompanied by pain and/or weakness of the thenar muscles which could affect thumb abduction and opposition [4].

Indicators of the disease are varied and include a combination of symptoms (e.g., paresthesia, tingling, and numbness), signs (e.g. Durkan's sign, Phalen's sign and Tinel's sign) and electrophysical studies $[1,5,6]$. CTR is effective in most cases.

A limited number of studies have highlighted the predictors of patients' outcomes and their satisfaction following CTR $[3-5,7]$

Identifying preoperative predictors of clinical outcomes and post-operative satisfaction provides more information for surgical planning and preoperative consultation [5]. The present study had two aims. The primary purpose of this study was to identify predictors of clinical outcomes after CTR. The secondary objective of this study was to evaluate patients' satisfaction and correlated predictors following CTR.

\footnotetext{
* Correspondence: hafez125@gmail.com

1 Department of Neurosurgery, Kermanshah University of Medical Sciences,

Imam Reza hospital, Kermanshah, Iran

Full list of author information is available at the end of the article
}

\section{Methods}

This prospective study was conducted in 2018. A sample of 152 patients with carpal tunnel syndrome who 
referred to the Imam Reza hospital, Kermanshah, Iran between April 2015 and April 2017, were included. Inclusion criteria were: age over 18 years, disease duration of at least 6 months and failure in medical treatment. Patients with a history of previous wrist surgery or trauma and those with diabetic neuropathy and cases with bilateral CTS were excluded. Moreover, 5 patients (3.03\%) left the follow up and 8 subjects (4.84\%) did not complete pre/postoperative forms [Fig. 1].

The present study was approved by the Scientific Research Board of the Kermanshah University of Medical Sciences. Informed written consent was obtained from all patients before enrolment.

Meticulous clinical examinations including specific provocative tests of the hand (Phalen's sign, Tinel's signs, and Durkan's tests), the Semmes-Weinstein monofilament test, and grip strength test were performed.

We performed the Semmes-Weinstein monofilament test at the most prominent finger for each patient. Results were recorded by a 5-point scale as follows: 1 - normal (2.83 monofilaments), 2-diminished light touch (3.61), 3diminished protective sensation (4.31), 4- loss of protective sensation (4.56), and 5-untestable sensation (6.65) [8]. Grip strength test was conducted using a Jamar dynamometer (Sammons Preston, Bolingbrook, Illinois) [3].

Electrophysiological tests were conducted pre-operatively for each patient. Sensory nerve action potential (SNAP) (in $\mu \mathrm{v}$ ), the peak latency of SNAP (in ms), the peak amplitude of compound muscle action potential (in $\mathrm{mV}$ ), and conduction velocity of the SNAP (in m/s) were recorded. According to the American Association of Electrodiagnostic
Medicine criteria [8] patients were categorized into three groups (mild, moderate and severe).

The Boston Carpal Tunnel Questionnaire (BCTQ) were assessed at intake and last follow -up visits to evaluate clinical outcomes.

Boston Carpal Tunnel Questionnaire (BCTQ) scores were recorded at preoperative visits and six-month postoperative visits. The BCTQ [6] is a disease-specific tool that can be used to assess symptom severity, functional status, and clinical outcome of patients with CTS. BCTQ is comprised of two separate parts: a symptom severity scale (SSS) and a functional status scale (FSS). The first part comprises 11 questions $(\mathrm{Q} 1 \sim \mathrm{Q} 11)$ concerning the severity of pain, tingling, numbness, and weakness. The functional status scale has 8 questions of activities of daily tasks. Each item scoring from 1 to 5 in the ascending order making a total score of 55 for SSS (with 11 being the best and 55 being the worst) and 40 for the FSS (with eight being the best and 40 being the worst). Mean Boston score for symptom severity and mean Boston score for functional status were obtained by dividing the total SSS by11 and total FSS by 8 . BCTQ was translated into the Persian language and it was validated. All patients were managed with the minimal invasive open technique for carpal tunnel release under local anesthesia.

Age, sex, hand dominancy, smoking, symptoms duration, body mass index (BMI), the Semmes-Weinstein monofilament test, grip strength, electrophysiological severity, scores of the Boston Carpal Tunnel Questionnaire, presence of positive physical examination signs (Phalen's sign, Tinel's signs and Durkan's tests), presence

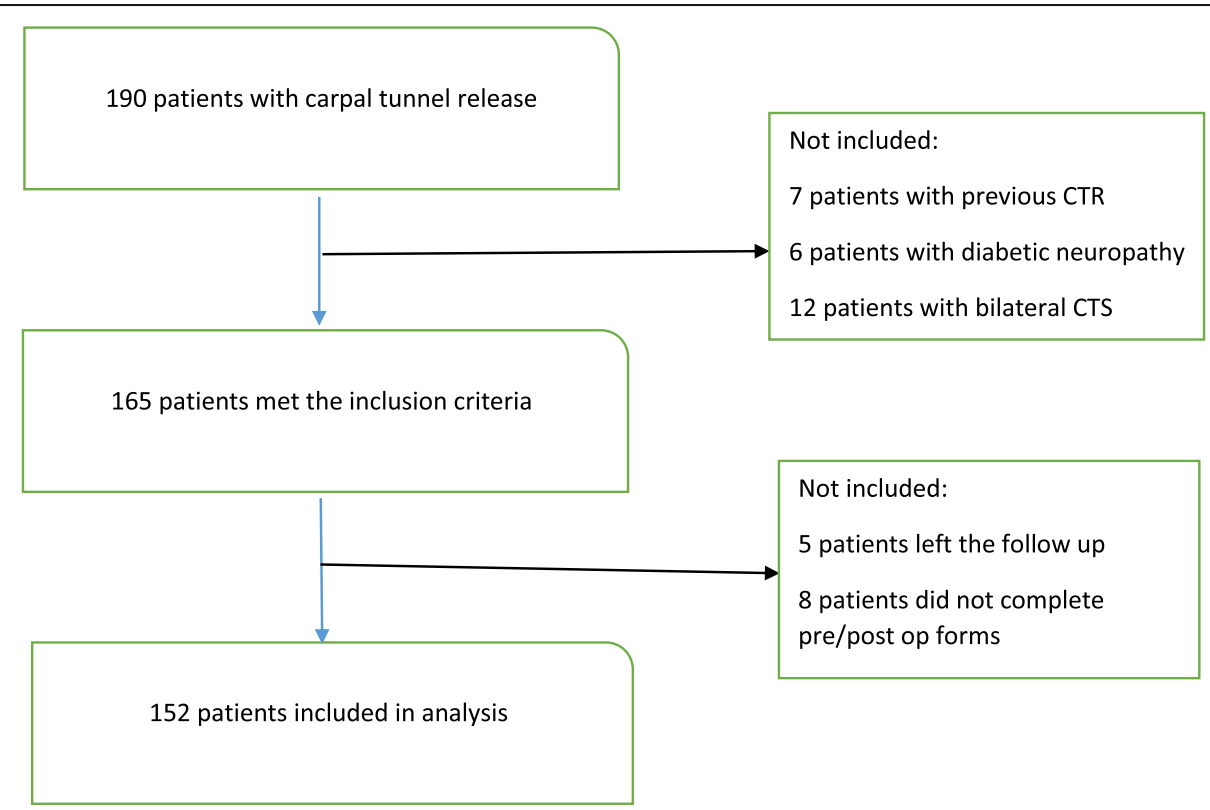

Fig. 1 Flowchart of the study population 
of thenar atrophy and EMG abnormalities (fibrillations, positive sharp waves or fasciculations) were selected as probable predictors of clinical outcomes and patients' satisfaction.

Patients' satisfaction was determined by a 10-point verbal descriptor nominal scale $(1=$ very poor, $5=$ fair, $10=$ excellent) and recorded, at last, follow -up visits.

\section{Statistical analysis}

Data analysis was performed with SPSS 21 (SPSS Inc. Chicago, Illinois). The mean and standard deviation of quantitative variables were calculated. The normality of quantitative variables was checked by the Kolmogorov -Smirnov test. The Wilcoxon test was used to compare preoperative SSS and FSS with 6- month postoperative SSS and FSS. Because the variables of pre-operative SSS, pre-operative FSS, Satisfaction, as well as change scores in SSS and FSS were nonnormal, we used nonparametric tests such as MannWhitney-U test, Kruskal Wallis, and Spearman correlation test for checking the relationship between mentioned variables with other variables and those that were significant entered into the linear regression model. It is notable, because dependent variables (pre-operative SSS, pre-operative FSS, Satisfaction, change score in SSS, and change score in FSS) were non-normal we take their logarithm (Ln) before doing regression tests. Significant level $<0.05$ considered as

Table 1 personal characteristics of the subjects

\begin{tabular}{|c|c|c|c|}
\hline Variables & & Frequency & Frequency percent \\
\hline \multirow[t]{2}{*}{ Gender } & Male & 34 & 22.4 \\
\hline & Female & 118 & 77.6 \\
\hline \multirow[t]{3}{*}{ Duration of symptoms } & One year & 16 & 10.5 \\
\hline & 1-4 year & 123 & 80.9 \\
\hline & $>$ four years & 13 & 8.6 \\
\hline \multirow[t]{3}{*}{ Electrophysiological severity } & Mild & 8 & 5.3 \\
\hline & Moderate & 72 & 47.4 \\
\hline & Sever & 72 & 47.4 \\
\hline \multirow[t]{2}{*}{ Involved side } & Dominant & 106 & 69.7 \\
\hline & Non dominant & 46 & 30.3 \\
\hline \multirow[t]{2}{*}{ Thenar muscle atrophy } & Absent & 132 & 86.8 \\
\hline & Present & 20 & 13.2 \\
\hline \multirow[t]{2}{*}{ Smoking } & No & 129 & 84.9 \\
\hline & Yes & 23 & 15.1 \\
\hline \multirow[t]{2}{*}{ Hypothyroidism } & No & 143 & 94.1 \\
\hline & Yes & 9 & 5.9 \\
\hline \multirow[t]{2}{*}{ Phalen test } & Positive & 135 & 88.8 \\
\hline & Negative & 17 & 11.2 \\
\hline \multirow[t]{2}{*}{ Tinel test } & Positive & 140 & 92.1 \\
\hline & Negative & 12 & 7.9 \\
\hline \multirow[t]{2}{*}{ Durkan test } & Positive & 141 & 92.8 \\
\hline & Negative & 11 & 7.2 \\
\hline \multirow[t]{2}{*}{ EMG abnormality } & Absent & 137 & 90.1 \\
\hline & Present & 15 & 9.9 \\
\hline \multirow[t]{5}{*}{ Monofilament test } & Normal & 8 & 5.3 \\
\hline & Diminished light touch & 50 & 32.9 \\
\hline & Diminished protective sensation & 92 & 60.5 \\
\hline & Loss of protective sensation & 2 & 1.3 \\
\hline & Loss of protective sensation & 2 & 1.3 \\
\hline \multirow[t]{2}{*}{ Previous carpal injection } & Yes & 61 & 40.13 \\
\hline & No & 91 & 59.86 \\
\hline
\end{tabular}


the significant level. $P$ values $<0.05$ considered as the significant level.

\section{Results}

There were 118 (77.6\%) females and 34 (22.36\%) males. The mean age was $50.50 \pm 7.24$ years. Sixteen (10.5\%) patients had CTS symptoms for less than 1 year, $123(80.9 \%)$ patients had symptoms for a period of 1 to 4 years, and 13(8.6\%) of our patients were symptomatic for more than 4 years. In $69.7 \%$ of patients (106 individuals), the dominant hand was involved. [Table 1].

\section{Predictors of pre-operative BCTQ (SSS \& FSS)}

The results of univariate analyses showed that the pre- operative SSS was related to age, duration of symptoms, electrophysiological severity, and the presence of thenar muscle atrophy $(P<0.05)$ [Table 2]. As well as, age, duration of symptoms, and the presence of thenar muscle atrophy were related to the preoperative FSS $(P<0.05)$ [Table 2]. According to the linear regression model, duration of symptoms and electrophysiological severity were the independent predictors of preoperative SSS. The model predicted $63 \%$ of the variance of pre-operative SSS [Table 3]. Meanwhile, linear regression model showed the age, duration of symptoms, and the presence of thenar muscle atrophy as the predictors of pre-operative FSS [Table 4].

\section{Predictors of change scores in SSS and FSS}

Overall, the result of the present study revealed that the surgery improved outcomes [Table 5]. Most variables did not have strong predictive power in clinical outcomes [Table 2]. However, duration of symptoms and electrophysiological severity were predictors of

Table 2 the relationship between various variables with pre-operative SSS, pre-operative FSS, satisfaction, and change scores in SSS and FSS

\begin{tabular}{|c|c|c|c|c|c|}
\hline Variables & Pre-operative SSS & Pre-operative FSS & Change score in SSS & Change score in FSS & $\overline{\text { Satisfaction }}$ \\
\hline Age & $\begin{array}{l}r=0.210 \\
P=0.009^{*}\end{array}$ & $\begin{array}{l}r=0.197 \\
P=0.015^{*}\end{array}$ & $\begin{array}{l}r=-0.196 \\
P=0.016^{*}\end{array}$ & $\begin{array}{l}r=0.226 \\
P=0.005^{*}\end{array}$ & $\begin{array}{l}r=-0.193 \\
P=0.017^{*}\end{array}$ \\
\hline Sex & $\begin{array}{l}Z=0.461 \\
P=0.645\end{array}$ & $\begin{array}{l}Z=-0.586 \\
P=0.558\end{array}$ & $\begin{array}{l}Z=-0.458 \\
P=0.647\end{array}$ & $\begin{array}{l}Z=-1.243 \\
P=0.214\end{array}$ & $\begin{array}{l}Z=-0.638 \\
P=0.524\end{array}$ \\
\hline BMI & $\begin{array}{l}r=0.087 \\
P=0.287\end{array}$ & $\begin{array}{l}r=0.005 \\
P=0.95\end{array}$ & $\begin{array}{l}r=0.037 \\
P=0.186\end{array}$ & $\begin{array}{l}r=0.044 \\
P=0.31\end{array}$ & $\begin{array}{l}r=-0.006 \\
P=0.937\end{array}$ \\
\hline Duration of symptom & $\begin{array}{l}K 2=8.006 \\
P=0.018^{*}\end{array}$ & $\begin{array}{l}K 2=8.007 \\
P=0.018^{*}\end{array}$ & $\begin{array}{l}K 2=8.093 \\
P=0.017^{*}\end{array}$ & $\begin{array}{l}K 2=2.638 \\
P=0.267\end{array}$ & $\begin{array}{l}K 2=0.725 \\
P=0.696\end{array}$ \\
\hline Electrophysiological Severity & $\begin{array}{l}K 2=99.896 \\
P<0.001^{*}\end{array}$ & $\begin{array}{l}K 2=1.894 \\
P=0.388\end{array}$ & $\begin{array}{l}K 2=99.786 \\
P<0.001^{*}\end{array}$ & $\begin{array}{l}K 2=2.927 \\
P=0.231\end{array}$ & $\begin{array}{l}K 2=2.69 \\
P=0.260\end{array}$ \\
\hline Involved side & $\begin{array}{l}Z=-0.339 \\
P=0.739\end{array}$ & $\begin{array}{l}Z=-0.437 \\
P=0.662\end{array}$ & $\begin{array}{l}Z=-0.359 \\
P=0.719\end{array}$ & $\begin{array}{l}Z=-0.594 \\
P=0.552\end{array}$ & $\begin{array}{l}Z=-0.178 \\
P=0.859\end{array}$ \\
\hline Grip strength & $\begin{array}{l}r=0.023 \\
P=0.779\end{array}$ & $\begin{array}{l}r=0.03 \\
P=0.71\end{array}$ & $\begin{array}{l}r=0.020 \\
P=0.805\end{array}$ & $\begin{array}{l}r=0.063 \\
P=0.443\end{array}$ & $\begin{array}{l}r=0.655 \\
P<0.001^{*}\end{array}$ \\
\hline Thenar muscle atrophy & $\begin{array}{l}Z=-3.039 \\
P=0.002^{*}\end{array}$ & $\begin{array}{l}Z=-2.392 \\
P=0.017^{*}\end{array}$ & $\begin{array}{l}Z=-3.084 \\
P=0.002^{*}\end{array}$ & $\begin{array}{l}Z=-1.072 \\
P=0.284\end{array}$ & $\begin{array}{l}Z=-1.561 \\
P=0.119\end{array}$ \\
\hline Smoking & $\begin{array}{l}Z=-0.533 \\
P=0.594\end{array}$ & $\begin{array}{l}Z=-0.240 \\
P=0.810\end{array}$ & $\begin{array}{l}Z=-0.497 \\
P=0.619\end{array}$ & $\begin{array}{l}Z=-0.067 \\
P=0.947\end{array}$ & $\begin{array}{l}Z=-0.497 \\
P=0.619\end{array}$ \\
\hline Hypothyroidism & $\begin{array}{l}Z=-1.345 \\
P=0.176\end{array}$ & $\begin{array}{l}Z=-0.730 \\
P=0.466\end{array}$ & $\begin{array}{l}Z=-1.306 \\
P=0.192\end{array}$ & $\begin{array}{l}Z=-0.145 \\
P=0.885\end{array}$ & $\begin{array}{l}Z=-0.057 \\
P=0.955\end{array}$ \\
\hline Phalen test & $\begin{array}{l}Z=-1.201 \\
P=0.230\end{array}$ & $\begin{array}{l}Z=-1.624 \\
P=0.104\end{array}$ & $\begin{array}{l}Z=-1.066 \\
P=0.287\end{array}$ & $\begin{array}{l}Z=-1.766 \\
P=0.077\end{array}$ & $\begin{array}{l}Z=-0.371 \\
P=0.710\end{array}$ \\
\hline Tinel test & $\begin{array}{l}Z=-0.88 \\
P=0.379\end{array}$ & $\begin{array}{l}Z=-0.390 \\
P=0.696\end{array}$ & $\begin{array}{l}Z=-0.859 \\
P=0.390\end{array}$ & $\begin{array}{l}Z=-0.531 \\
P=0.595\end{array}$ & $\begin{array}{l}Z=-0.423 \\
P=0.672\end{array}$ \\
\hline Durkan test & $\begin{array}{l}Z=-1.439 \\
P=0.150\end{array}$ & $\begin{array}{l}Z=1.126 \\
P=0.260\end{array}$ & $\begin{array}{l}Z=-1.385 \\
P=0.166\end{array}$ & $\begin{array}{l}Z=-0.790 \\
P=0.430\end{array}$ & $\begin{array}{l}Z=-0.130 \\
P=0.897\end{array}$ \\
\hline EMG abnormality & $\begin{array}{l}Z=-0.365 \\
P=0.715\end{array}$ & $\begin{array}{l}Z=-0.225 \\
P=0.822\end{array}$ & $\begin{array}{l}Z=-0.381 \\
P=0.704\end{array}$ & $\begin{array}{l}Z=-0.627 \\
P=0.531\end{array}$ & $\begin{array}{l}Z=-0.415 \\
P=0.678\end{array}$ \\
\hline Monofilament test & $\begin{array}{l}K 2=0.445 \\
P=0.931\end{array}$ & $\begin{array}{l}K 2=7.56 \\
P=0.056\end{array}$ & $\begin{array}{l}K 2=0.604 \\
P=0.896\end{array}$ & $\begin{array}{l}K 2=4.705 \\
P=0.195\end{array}$ & $\begin{array}{l}\mathrm{K} 2=4.780 \\
P=0.189\end{array}$ \\
\hline Previous carpal injection & $\begin{array}{l}Z=3.71 \\
P=0.151\end{array}$ & $\begin{array}{l}Z=1.18 \\
P=0.554\end{array}$ & $\begin{array}{l}Z=3.881 \\
P=0.275\end{array}$ & $\begin{array}{l}K Z=7.50 \\
P=0.067\end{array}$ & $\begin{array}{l}Z=3.861 \\
P=0.277\end{array}$ \\
\hline
\end{tabular}


Table 3 predicting pre-operative SSS by variables of age, duration of symptoms, electrophysiological severity, and thenar muscle atrophy

\begin{tabular}{|c|c|c|c|c|c|}
\hline Predictors & B & Standard error & Sig. & Standard coefficient Beta & $\mathrm{Cl} 95 \%$ \\
\hline Constant & 2.903 & 0.080 & $<0.001$ & - & $2.746-3.060$ \\
\hline Age & 0.002 & 0.001 & 0.111 & 0.08 & $0.001-0.004$ \\
\hline Duration of symptoms & 0.053 & 0.019 & $* 0.007$ & 0.134 & $0.015-0.019$ \\
\hline Electrophysiological severity & 0.225 & 0.015 & $*<0.001$ & 0.776 & $0.195-0.255$ \\
\hline Thenar muscle atrophy & -0.006 & 0.026 & 0.822 & -0.012 & $-0.059-0.046$ \\
\hline \multicolumn{6}{|l|}{ Model summary } \\
\hline Model & $\mathrm{R}$ & R2 & Adjusted R2 & & \\
\hline $\begin{array}{l}\text { Age, duration of symtoms, electrophysiological } \\
\text { severity, thenar muscle atrophy }\end{array}$ & 0.804 & 0.647 & 0.637 & & \\
\hline
\end{tabular}

Dependent variable: Ln SSS pre-operation

the change score in SSS $(P<0.05)$ [Table 6]. Moreover, age was the only predictor of change scores in FSS $(P<0.05)$ [Table 7].

\section{Predictors of post-operative satisfaction}

At first, we assessed the relationship between postoperative satisfaction and suggested variables. The variables of age and preoperative grip strength were correlated with the patients' satisfaction $(P<0.05)$ [Table 3]. In the next step, we conducted a linear regression model. Interestingly, the result of the regression model showed the preoperative grip strength as the powerful predictor of post-operative satisfaction $(B=0.026, \quad P<0.001)$. However, the model did not show such a strong predictive power for age $(B=-0.003, P=0.043)$. Overall, the model predicted $73 \%$ of the variance of post-operative satisfaction [Table 8].

Critical complications such as tendon, muscle or nerve damages were not observed in the study.

Table 4 predicting pre-operative FSS by variables of age, duration of symptoms, and thenar muscle atrophy

\begin{tabular}{|c|c|c|c|c|c|}
\hline Predictors & $B$ & $\begin{array}{l}\text { Standard } \\
\text { error }\end{array}$ & Sig. & $\begin{array}{l}\text { Standard } \\
\text { coefficient } \\
\text { Beta } \\
\end{array}$ & $\mathrm{Cl} 95 \%$ \\
\hline Constant & 0.937 & 0.121 & $<0.001$ & - & $0.697-1.176$ \\
\hline Age & 0.004 & 0.002 & ${ }^{*} 0.020$ & 0.185 & $0.001-0.008$ \\
\hline $\begin{array}{l}\text { Duration of } \\
\text { symptoms }\end{array}$ & $\overline{-}-063$ & 0.030 & ${ }^{*} 0.037$ & -0.165 & $0.122-0.004$ \\
\hline $\begin{array}{l}\text { Thenar muscle } \\
\text { atrophy }\end{array}$ & 0.081 & 0.039 & ${ }^{*} 0.037$ & 0.165 & $0.005-0.157$ \\
\hline \multicolumn{6}{|l|}{ Model summary } \\
\hline Model & R & R2 & \multicolumn{3}{|c|}{ Adjusted R2 } \\
\hline $\begin{array}{l}\text { Age, duration of } \\
\text { symtoms, thenar } \\
\text { muscle atrophy }\end{array}$ & 0.309 & 0.095 & \multicolumn{3}{|l|}{0.077} \\
\hline
\end{tabular}

\section{Discussions}

Carpal tunnel syndrome is the most common peripheral neuropathy [9]. Carpal releasing surgery proved to be effective in many cases, although reported success varies. The incidence of CTS is increasing as $11 \%$ of females and $3.5 \%$ of males, with increasing life expectancy [10].

Open release of the carpal tunnel, introduced by Phalen et al. (1950) is the standard treatment for the CTS [11]. According to a recent review of a longterm follow-up after CTS surgery, clinical success reported between 75 and 90\% [1]. In spite of the considerable improvement in patients' symptoms, their satisfaction with releasing surgery is still unpredictable. In the present study, we have evaluated the predictors of clinical outcomes and satisfaction of patients with CTR.

The Boston carpal tunnel syndrome questionnaire is a disease-specific measure [6]. The sensitivity of the Boston CTS Questionnaire for detecting a change after carpal tunnel surgery has been demonstrated [6]. Gay et al. found that the BCTQ is more sensitive to changes in clinical stats of patients than the electrophysiological findings, clinical examination or other generic questionnaires such as the Short-Form 36 and Disabilities of the Arm, Shoulder, and Hand questionnaire [12].

Table 5 comparison of pre and post- operative SSS and FSS variables by Wilcoxon test

\begin{tabular}{lllll}
\hline \multicolumn{2}{l}{ Variables } & Mean rank & Mean + SD & Statistical test \\
\hline SSS & Pre-operative & 76.33 & $38.65 \pm 6.22$ & $Z=-10.69$ \\
& Post-operative & 0.00 & $1.29 \pm 0.48$ & $P<0.001$ \\
FSS & Pre-operative & 73.50 & $3.10 \pm 0.49$ & $Z=-10.80$ \\
& Post-operative & 0.00 & $1.68 \pm 0.48$ & $P<0.001$ \\
\hline
\end{tabular}


Table 6 predicting change score in SSS by variables of age, duration of symptoms, and electrophysiological severity

\begin{tabular}{|c|c|c|c|c|c|}
\hline Predictors & B & Standard error & Sig. & Standard coefficient Beta & Cl 95\% \\
\hline Constant & 2.844 & 0.084 & $<0.001$ & - & $2.678-3.011$ \\
\hline Age & 0.002 & 0.001 & 0.134 & 0.077 & $-0.001-0.004$ \\
\hline Duration of symptoms & 0.056 & 0.20 & ${ }^{*} 0.007$ & 0.137 & $0.015-0.096$ \\
\hline Electrophysiological severity & 0.231 & 0.016 & ${ }^{*}<0.001$ & 0.767 & $0.199-0.263$ \\
\hline Thenar muscle atrophy & -0.003 & 0.028 & 0.908 & -0.006 & $-0.58-0.052$ \\
\hline \multicolumn{6}{|l|}{ Model summary } \\
\hline Model & $\mathrm{R}$ & R2 & \multicolumn{3}{|c|}{ Adjusted R2 } \\
\hline $\begin{array}{l}\text { Age, duration of symtoms, electrophysiological severity, } \\
\text { Thenar muscle atrophy }\end{array}$ & 0.796 & 0.634 & \multicolumn{3}{|l|}{0.624} \\
\hline
\end{tabular}

Some factors have been suggested as outcome predictors of carpal releasing surgery including age, gender, smoking, occupation, underlying disease, duration of symptoms, and preoperative muscle weakness or atrophy $[7,8]$ However, in this study, most variables did not have a strong predictive value on patients' outcomes. In our study, patients with severe electrophysiological findings had higher postoperative FSS score. This finding suggests that early diagnosis and treatment of carpal tunnel syndrome could improve clinical outcomes.

Moreover, our results did not demonstrate a relationship between clinical outcomes and the duration of symptoms. Eisenhardt et al. reported a recovery period of 16 days in patients whose symptoms lasted less than 1 year compared to 25 days of recovery in patients with duration of symptoms more than 1 year [13]. They found that the duration of paresthesia did not have a significant effect on the outcome of CTR [13].

Grip strength can be decreased by CTS significantly which can lead to losing productivity at work and daily activities [14]. This study concluded that patients with a weaker preoperative grip strength had lower satisfaction following a CTR. Brown et al. reported that patients with reduced grip strength require longer postoperative duration to recover the grip strength and the recovery is also incomplete.
They have suggested that this may be due to progressive median nerve damage in long-standing CTS [11]. Levine et al. reported that patients' satisfaction had a moderate correlation with the improvement of the functional status score and highly with changes in the symptom severity scale score and a moderate correlation with the change of the functional status score [6].

The relationship between age and patients' satisfaction after CTR is not well documented. Results of our study revealed a correlation between age and postoperative satisfaction. Hansen and Larsen [15] reported that patients over 65 years old had less favorable results on the BCTQ after CTR. They concluded that age may have an adverse effect on nerve regeneration. Atroshi et al. found that age was a significant predictor of patient dissatisfaction [16].

\section{Strength and limitations}

This study has shown to be powerful in three main areas: First, a large sample of patients, second, organized and detailed data on symptoms and third, a systemized physical examination.

This study had limitations. We measured patients' satisfaction only at 6 months after CTS surgery. However, studies with longer follow-up periods showed that the persistence of positive effects had no further improvement beyond 6 months $[4,17,18]$.

Table 7 predicting change score in FSS by variable of age

\begin{tabular}{llllll}
\hline Predictors & B & Standard error & Sig. & Standard coefficient Beta & Cl 95\% \\
\hline Constant & -0.193 & 0.211 & 0.362 & - & $-0.610-0.224$ \\
Age & 0.010 & 0.004 & 0.015 & 0.201 & $0.002-0.018$ \\
Model summary & & & & & \\
Model & R & R2 & Adjusted R2 & & \\
VAge & 0.201 & 0.041 & 0.034 & & \\
\hline
\end{tabular}


Table 8 predicting satisfaction by grip strength and age by linear regression test

\begin{tabular}{llllll}
\hline Predictors & $\mathrm{B}$ & Standard error & Sig. & Standard coefficient Beta & Cl 95\% \\
\hline Constant & 1.355 & 0.048 & $<0.001$ & - & $1.26-1.45$ \\
Grip strength & 0.026 & 0.002 & $<0.001$ & 0.77 & $0.023-0.030$ \\
Constant & 1.49 & 0.85 & $<0.001$ & - & $1.33-1.66$ \\
Grip strength & 0.026 & 0.002 & $<0.001$ & 0.759 & $0.023-0.030$ \\
Age & -0.003 & 0.001 & 0.043 & -0.005 & 0.001 \\
Model summary & & & & Adjusted R2 \\
$\quad$ Model & $\mathrm{R}$ & $\mathrm{R} 2$ & & \\
$\quad$ Grip strength & 0.770 & 0.593 & 0.590 & \\
$\quad$ Grip strength and age & 0.777 & 0.604 & & & \\
\hline
\end{tabular}

Dependent variable: Ln satisfaction

Furthermore, there was a substantial drop-out rate among patients between the intake and the follow-up at 6 months.

Conclusions: Results of the present study revealed that there was a significant improvement in clinical outcomes after CTS surgery. Stronger pre-operative grip strength and younger age were independent predictors of higher post-operative satisfaction. These results can be used in pre-operative counseling and management of postoperative expectations.

\section{Abbreviations}

BCTQ: Boston Carpal Tunnel Questionnaire; CTR: Carpal Tunnel Release; CTS: Carpal Tunnel Syndrome; CTS: Symptom Severity Scale; FSS: Functional Status Scale

\section{Acknowledgments}

We appreciate the Clinical Research Development Center of Taleghani and Imam Ali Hospital for their wise advice.

\section{Authors' contributions}

EA and SRB had the idea for this study. EA and PR participated in outlining the concept and design. $\mathrm{HH}$ and $\mathrm{AA}$ did the data acquisition. EA and AA did the statistical analysis and wrote the first draft of the manuscript. EA, SRB, $\mathrm{HH}$, and AA revised the final manuscript. All authors have read and approved the manuscript.

\section{Funding}

There was no external source of funding.

\section{Availability of data and materials}

All data are available from the corresponding author upon reasonable request.

\section{Ethics approval and consent to participate}

The study received ethics approval by the Kermanshah University of Medical Science Ethics Committee. Written consent to participate was obtained from all patients.

\section{Consent for publication}

Not applicable.

\section{Competing interests}

The authors declare that they have no competing interests.

\section{Author details}

'Department of Neurosurgery, Kermanshah University of Medical Sciences, Imam Reza hospital, Kermanshah, Iran. ²Department of Neurosurgery,
University of Medical Sciences, Imam Reza hospital, Kermanshah, Iran. ${ }^{3}$ Clinical Research Development Center, Taleghani and Imam Ali Hospital, Kermanshah University of Medical Sciences, Kermanshah, Iran. ${ }^{4}$ operating room department, Kermanshah University of Medical Sciences, Imam Reza hospital, Kermanshah, Iran. ${ }^{5}$ nursing and midwifery school, Kermanshah University of Medical Sciences, Imam Reza hospital, Kermanshah, Iran.

Received: 22 September 2019 Accepted: 20 January 2020

Published online: 28 January 2020

\section{References}

1. Louie D, Earp B, Blazar P. Long-term outcomes of carpal tunnel release: a critical review of the literature. Hand (New York, NY). 2012;7(3):242-6.

2. Bae JY, Kim JK, Yoon JO, Kim JH, Ho BC. Preoperative predictors of patient satisfaction after carpal tunnel release. Orthop Traumatol Surg Res. 2018; 104(6):907-9.

3. Beck JD, Brothers JG, Maloney PJ, Deegan JH, Tang X, Klena JC. Predicting the outcome of revision carpal tunnel release. J Hand Surg. 2012;37(2):2827.

4. Carmona L, Faucett J, Blanc PD, Yelin E. Predictors of rate of return to work after surgery for carpal tunnel syndrome. Arthritis Care Res. 1998;11(4):298305.

5. Dyer G, Lozano-Calderon S, Gannon C, Baratz M, Ring D. Predictors of acute carpal tunnel syndrome associated with fracture of the distal radius. J Hand Surg. 2008;33(8):1309-13

6. Levine DW, Simmons BP, Koris MJ, Daltroy LH, Hohl GG, Fossel AH, et al. A self-administered questionnaire for the assessment of severity of symptoms and functional status in carpal tunnel syndrome. J Bone Joint Surg Am. 1993;75(11):1585-92

7. Werner RA, Gell N, Franzblau A, Armstrong TJ. Prolonged median sensory latency as a predictor of future carpal tunnel syndrome. Muscle Nerve. 2001 24(11):1462-7.

8. Chen AC, Wu MH, Cheng CY, Chan YS. Outcomes and satisfaction with endoscopic carpal tunnel releases and the predictors - a retrospective cohort study. Open Orthop J. 2016:10:757-64

9. Lo JK, Finestone HM, Gilbert K. Prospective evaluation of the clinical prediction of electrodiagnostic results in carpal tunnel syndrome. PM R. 2009;1 (7):612-9.

10. Visser LH, Ngo Q, Groeneweg SJ, Brekelmans G. Long term effect of local corticosteroid injection for carpal tunnel syndrome: a relation with electrodiagnostic severity. Clin Neurophysiol. 2012;123(4):838-41.

11. Brown RA, Gelberman RH, Seiler JG 3rd, Abrahamsson SO, Weiland AJ, Urbaniak JR, et al. Carpal tunnel release. A prospective, randomized assessment of open and endoscopic methods. J Bone Joint Surg Am. 1993; 75(9):1265-75.

12. Gay RE, Amadio PC, Johnson JC. Comparative responsiveness of the disabilities of the arm, shoulder, and hand, the carpal tunnel questionnaire, and the SF-36 to clinical change after carpal tunnel release. J Hand Surg. 2003;28(2):250-4.

13. Eisenhardt SU, Mathonia C, Stark GB, Horch RE, Bannasch H. Retrospective analysis of 242 patients whose carpal tunnels were released using a one- 
port endoscopic procedure: superior results of early intervention. J Plast Surg Hand Surg. 2010;44(6):311-7.

14. Edgell SE, McCabe SJ, Breidenbach WC, LaJoie AS, Abell TD. Predicting the outcome of carpal tunnel release. J Hand Surg. 2003;28(2):255-61.

15. Hansen TB, Larsen K. Age is an important predictor of short-term outcome in endoscopic carpal tunnel release. J Hand Surg Eur Vol. 2009;34(5):660-4.

16. Atroshi I, Johnsson R, Ornstein E. Patient satisfaction and return to work after endoscopic carpal tunnel surgery. J Hand Surg. 1998;23(1):58-65.

17. Zwolinska J, Kwolek A. Factors determining the effectiveness of conservative treatment in patients with carpal tunnel syndrome. Int J Occup Med Environ Health. 2019;32(2):197-215.

18. Louie DL, Earp BE, Collins JE, Losina E, Katz JN, Black EM, et al. Outcomes of open carpal tunnel release at a minimum of ten years. J Bone Joint Surg Am. 2013;95(12):1067-73.

\section{Publisher's Note}

Springer Nature remains neutral with regard to jurisdictional claims in published maps and institutional affiliations.

Ready to submit your research? Choose BMC and benefit from:

- fast, convenient online submission

- thorough peer review by experienced researchers in your field

- rapid publication on acceptance

- support for research data, including large and complex data types

- gold Open Access which fosters wider collaboration and increased citations

- maximum visibility for your research: over $100 \mathrm{M}$ website views per year

At $\mathrm{BMC}$, research is always in progress.

Learn more biomedcentral.com/submissions 